\title{
Editorial: Three years beyond the crossroads - the road ahead for public policy
}

\author{
Editorial Team*
}

\begin{abstract}
In the run up to the last general election in 2010, PPP published a special issue on the future direction of public policy. Contributors were asked to peer through the murky waters of electioneering to analyse what challenges lay ahead. Looking back, the contributors provided some prescient insights: Rotherham warned of the disproportionate implications of squeezed budgets on environmental policy; Crowe, Dayson and Wells looked at the likely retrenchment of public services and the consequent impact on Third Sector providers; and Fothergill noted the risks of a continued focus on supply-side labour market solutions, hinting at the impacts of this on 'old industrial' Britain in a context of UK-wide recession.
\end{abstract}

The three years since the 2010 General Election have seen both discourse and policy transformed by the Coalition Government's programme of reform under the rubric of 'austerity'. Few of our contributors back in 2010 predicted the near radical zeal with which the Coalition Government would reconfigure state spending and the delivery of public services. In the midst of Party Conference season, as mainstream political parties set out their stall for the next General Election in 2015, we feel we are at a critical juncture to take stock of recent developments. We have therefore invited national experts to reflect critically on policy under the Coalition Government and how policymakers will or should respond to challenges across six key policy domains:

- labour markets

- migration

- planning

- urban policy and regeneration

- the third sector

- the environment.

Contributors responded to this invitation in a variety of ways, including wide-ranging critiques of existing, and often long-standing, approaches to labour market policy (Fothergill), regeneration (Lupton) and migration (Robinson); discussion of the Coalition Government's record on planning (Goodchild and Hammond) and the environment (While); and more holistic reflection of the contemporary 'state of the Third Sector' (Dayson and Wells). But there are also strong commonalities in terms of key concerns: the spectre of drastic spending cuts and sluggish growth; the reconfiguration of service delivery and the opportunities and constraints it presents for the public, private and third sectors; the uneven impact of discourses and policies that serve to reinforce 
social and spatial inequalities; and the flawed assumptions underpinning policies that are only loosely, if at all, evidence based.

These concerns raise important questions for those engaged in policy-focused research. On the one hand, it highlights the importance of academics shining a critical light on existing and future policy given its perceived failing to tackle contemporary issues. It is striking that none of the contributors suggest existing policies are working. On the other hand, the apparent indifference or disregard of often years of academic insights suggests that evidence based policy making is something of a misnomer. In such circumstances, appeals to heed evidence may have little influence over political debates and the decisions of policymakers.

Nonetheless, the routes from academic research to politics are opaque and influence cannot always be measured. At the very least, applied research has the potential to build a body of evidence that leads to incremental change. Moreover, it can also play a role in influencing decision-makers and practitioners outside of central government. This fits with the core aim of of PPP to shape debates around policy and practice at all levels.

Finally, it should perhaps be remembered that academics can also play a wider role beyond collecting and presenting evidence to shape policy. Our analysis can, and arguably should, extend to how policy is formulated. As Manzi and Jacobs (2013) argue in the previous edition of PPP, evidence is just one set of 'rationalities' that leads policymakers to the make the decisions they do. As we move towards the next General Election, we hope that PPP can continue to perform that dual role of building an evidence base whilst critically deconstructing the policy-making process.

Correspondence Address: Centre for Regional Economic and Social Research, Sheffield Hallam University, Unit 10, Science Park, Howard Street, Sheffield, S1 1 WB. Email: ppponline@shu.ac.uk. 